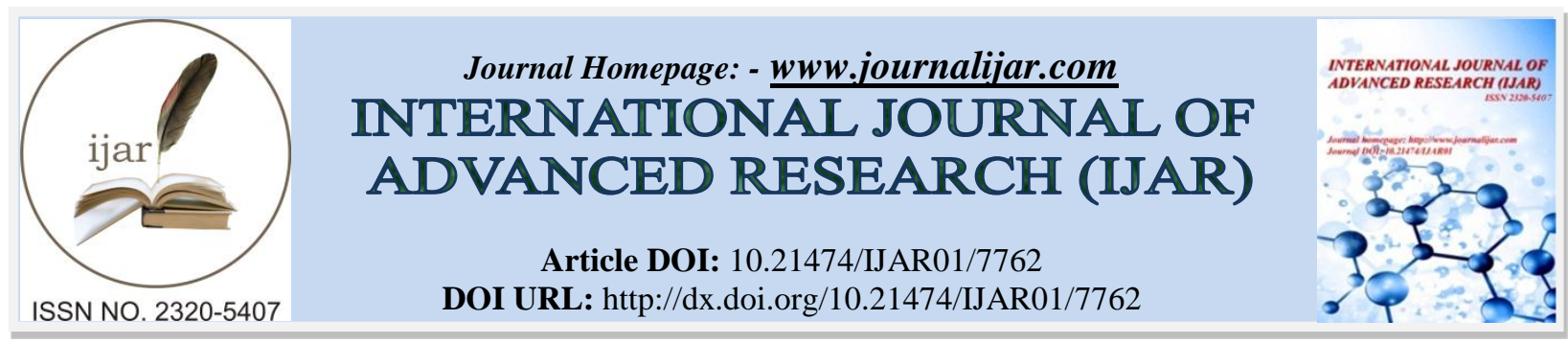

RESEARCH ARTICLE

\title{
SOL-GEL SYNTHESIS AND DIELECTRIC PROPERTIES OF SAMARIUM DOPED NANOCRYSTALLINE COBALT ZINC FERRITE.
}

\author{
Shete S. B. \\ Department of Electronics, S.G.B.CollegePurna, - 431511, India.
}

\section{Manuscript Info}

Manuscript History

Received: 25 July 2018

Final Accepted: 31 August 2018

Published: September 2018

Keywords:-

Sol gel synthesis, Dielectric constant,

Dielectric loss, Loss tangent, AC

conductivity.

\begin{abstract}
Polycrystalline $\mathrm{Co}_{0.7} \mathrm{Zn}_{0.3} \mathrm{Sm}_{\mathrm{y}} \mathrm{Fe}_{2-\mathrm{y}} \mathrm{O}_{4}$ with y varying from 0.0 to 0.4 has been prepared by sol- gel auto combustion route. Dielectric properties such as dielectric constant and dielectric loss were studied as a function of $\mathrm{Sm}^{3+}$ substitution and frequency. Dielectric constant decreases with increasing frequency. The dielectric behavior was explained on the basis of interfacial polarization according to Koops theory. Variation of $\mathrm{AC}$ conductivity with frequency confirms the conduction due to $\mathrm{p}$ and n-type charge carriers.
\end{abstract}

Copy Right, IJAR, 2018,. All rights reserved.

\section{Introduction:-}

The magnetic and dielectric behavior of ferrite nanoparticles has been recently implemented in various technological applications [1,2]. The dielectric properties of the ferrite nanoparticles play important role in advanced technology, for example electromagnetic interface shielding, supercapacitors, sensors [3-5]. The dielectric behavior of the iron rich oxides is due to dipolar moments between divalent and trivalent cations [6]. The spinel ferrite shows unique properties as low eddy current loses, high electrical resistivity and low dielectric loss at high frequency [7]. The polarization in spinel ferrite is due to hopping of electron and holes [8]. The hopping is found to be dependent on type of cations as well as grain and grain boundary in spinel structure [9]. The charge polarization can be modified by replacement of $\mathrm{Fe}(\mathrm{III})$ ions by the other trivalent ions in spinel ferrite [10]. The cobalt ferrite shows n-type semiconducting nature and electron hopping is dominant [11].

The rare-earth ions substitution within the spinel ferrite emerged as a promising strategy to improve the performance of spinel ferrite. The aim of this strategy is to improve structure, grain size, grain boundaries and type of semiconducting nature of spinel ferrite. Various synthesis methods have been reported for preparation of nano-size spinel ferrite such as ceramic method, chemical co-precipitation method, chemical spray method and sol-gel auto combustion method [12-15]. In this context, most suitable low cost less time consuming portable sol gel method for synthesis of Sm doped cobalt ferrite is being persued.

In present studies, the effect of $\mathrm{Sm}^{3+}$ doping on dielectric constant dielectric loss and A. C. electrical conductivity of $\mathrm{Co}_{0.7} \mathrm{Zn}_{0.3} \mathrm{Sm}_{\mathrm{y}} \mathrm{Fe}_{2-\mathrm{y}} \mathrm{O}_{4}$ ferrite nanocrystals synthesized by sol-gel auto combustion method have been studied.

\section{Experimental}

\section{Synthesis method}

All reagents were of analytical grade and used without further purification. Required amount of $\mathrm{Co}\left(\mathrm{NO}_{3}\right)_{2} \cdot 6 \mathrm{H}_{2} \mathrm{O}$ (Cobalt Nitrate), $\mathrm{Zn}\left(\mathrm{NO}_{3}\right)_{2} \cdot 6 \mathrm{H}_{2} \mathrm{O}$ (Zinc Nitrate), $\mathrm{Sm}\left(\mathrm{NO}_{3}\right)_{3} \cdot 6 \mathrm{H}_{2} \mathrm{O}$ (Samarium Nitrate), $\mathrm{Fe}\left(\mathrm{NO}_{3}\right)_{3} \quad 9 \mathrm{H}_{2} \mathrm{O}$ (Ferric 
Nitrate); and citric acid $\mathrm{C}_{6} \mathrm{H}_{8} \mathrm{O}_{7} \cdot \mathrm{H}_{2} \mathrm{O}$ with $99.9+\%$ purity by s. d. fine, India were dissolved in de-ionized water. Molar ratio of metal nitrate to citrate was kept as $3: 1$ for $\mathrm{Co}_{0.7} \mathrm{Zn}_{0.3} \mathrm{Sm}_{\mathrm{y}} \mathrm{Fe}_{2-\mathrm{y}} \mathrm{O}_{4}$ composition. All the metals and citrate solution were transferred to $1000 \mathrm{ml}$ beaker; the $\mathrm{pH} \approx 7$ of the mixture solution was maintained by adding ammonium hydroxide solution. Then the solution kept on hot plate with continuous stirring at $100^{\circ} \mathrm{C}$. The solution was slowly got evaporated and finally turned into thick viscous gel. When all water molecules get consumed the gel automatically ignited and turned into fine ashes as the final product. The ash was crushed with the help of agate mortar pestle to get fine powder. Finally all the powders were heated at $500^{\circ} \mathrm{C}$ for $6 \mathrm{~h}$ in hot air oven to remove all impurities and used for further characterization.

\section{Characterization techniques}

The dielectric measurements were confirmed by two probe technique. The measurements were taken at room temperature. The dielectric constant $\left(\varepsilon^{\prime}\right)$, dielectric loss $\left(\varepsilon^{\prime \prime}\right)$ and dielectric loss tangent (tan $\left.\delta\right)$ and AC conductivity were measured as a function of frequency by using (LCR Hi Tester 3520-50) LCR-Q meter.

\section{Result and discussion:-}

The variation of dielectric constant $\left(\varepsilon^{\prime}\right)$ and dielectric loss $\left(\varepsilon^{\prime \prime}\right)$ as a function of frequency at room temperature for all samples are shown in figure $1 \mathrm{a}$ and $1 \mathrm{~b}$ respectively. From figure it is observed that dielectric constant $\left(\varepsilon^{\prime}\right)$ and dielectric loss $\left(\varepsilon^{\prime \prime}\right)$ decreases very rapidly with increasing frequency and remains independent of applied field at high frequency this is common behavior observed in ferrite. The Maxwell-Wanger [16, 17] model explain conduction in ferrite, dielectric materials are assumed to be composed of conduction grains separated by less conducting grain boundaries. The polarization in polycrystalline ferrite is reported to be hopping of electrons between ions of same elements in different oxidation state at B site [18]. When alternating field is applied, the electrons move in the direction of field through the grains by hopping and accumulate at the grain boundaries to produce polarization. When frequency of field increases electrons cannot keep up with field and lag behind the field. As a result electrons reaching the grain boundaries decreases; this decreases the polarization and hence the dielectric constant and dielectric loss decreases. In the present study with substitution of samarium content both dielectric constant $\left(\varepsilon^{\prime}\right)$ and dielectric loss $\left(\varepsilon^{\prime \prime}\right)$ decreases which can be attributed to the increase in grain size. Increase in grain size decreases both number of grains and grain boundaries, result in decrease of the polarization. Similarly Sm ${ }^{3+}$ occupy both tetrahedral A site and octahedral $\mathrm{B}$ site replaces $\mathrm{Fe}^{3+}$ ions in $\mathrm{B}$ sites and decrease $\mathrm{Fe}^{3+} \leftrightarrow \mathrm{Fe}^{2+}$ ions on $\mathrm{B}$ site. exchange process of $\mathrm{Co}^{2+}$ and $\mathrm{Co}^{3+}$ is weak compared to $\mathrm{Fe}^{3+} \leftrightarrow \mathrm{Fe}^{2+}$, hence $\mathrm{Fe}^{3+}-\mathrm{Fe}^{2+}$ is assume to be dominant mechanism .

\section{Dielectric Loss tangent $(\tan \delta)$}

Figure $2 \mathrm{~b}$ shows variation of dielectric loss tangent $\tan \delta$ with frequency for all composition. The dielectric loss tangent is large at lower frequency and it decreases with increasing frequency. The tan $\delta$ is the energy dissipation in dielectric system which is proportional to the imaginary part of dielectric constant $\left(\varepsilon^{\prime \prime}\right)$. The dielectric loss tangent depends upon number of factors such as $\mathrm{Fe}^{2+}$ content, stoichiometry, structure, and homogeneity and particle size. At low frequency resistivity of materials is high; more energy is required to exchange of electron between Fe ${ }^{2+}$ and $\mathrm{Fe}^{3+}$ ions and thus energy loss is high. In the high frequency range, which corresponds to low resistivity a small energy is needed for electron exchange between $\mathrm{Fe}^{2+}$ and $\mathrm{Fe}^{3+}$ ions in the grains and accompanied by a small eddy current and hence a decrease in energy loss.[19].
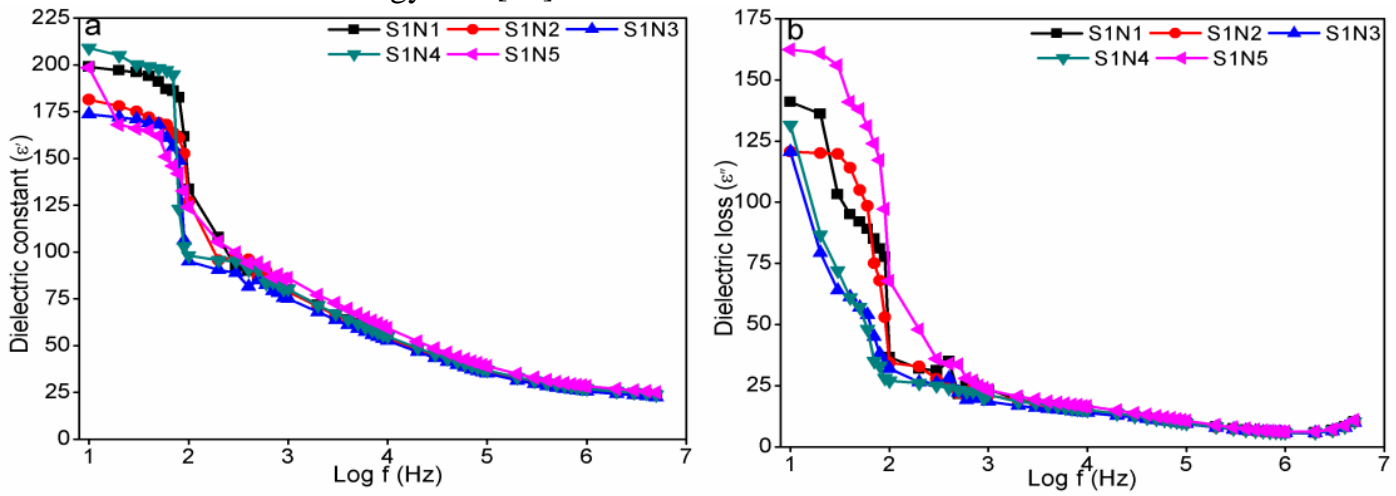

Fig.3 (a) Variation of dielectric constant, (b) dielectric loss with frequency 

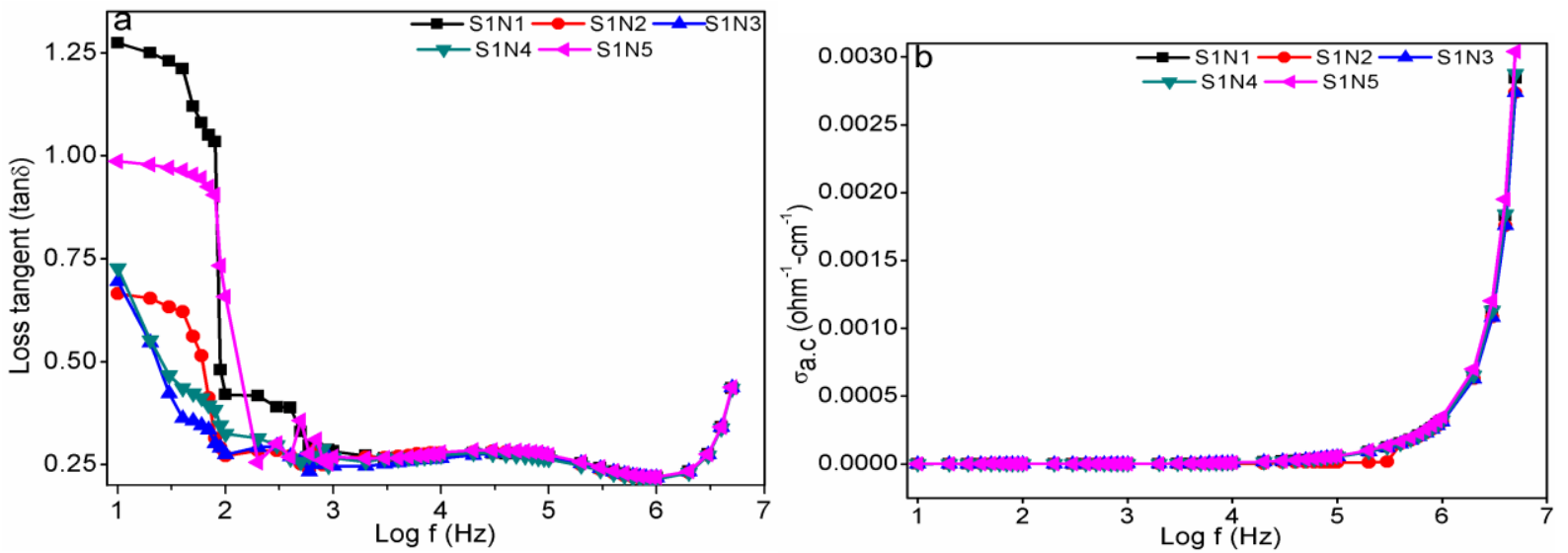

Fig. 3 Variation of (a) dielectric loss tangent, (b) A. C. Conductivity with frequency

\section{A.C Conductivity:-}

The variation of a.c. conductivity with frequency of $\mathrm{Co}_{0.7} \mathrm{Zn}_{0.3} \mathrm{Sm}_{\mathrm{y}} \mathrm{Fe}_{2-\mathrm{y}} \mathrm{O}_{4}$ at room temperature is shown in figure $2 \mathrm{~b}$. It is observed that a.c conductivity increase with increasing frequency. The conduction in ferrite can takes place with the help of formation of $\mathrm{Fe}^{3+}$ and $\mathrm{Fe}^{2+}$ ions at octahedral B site and electron exchange between them; i.e. the hopping of electrons through the grains which result in conduction. The hopping rate is frequency dependent. As frequency of applied field increases the hopping rate increases which increases the conductivity. The enhancement of conductivity at high frequency is not due to increased concentration of charge carriers but it is due to rate of mobility of charge carriers. In the present study a.c conductivity decreases with the increasing samarium concentration ' $x$ ' this is because doping of $\mathrm{Sm}^{3+}$ increases the size of grain $\left(\mathrm{Sm}^{3+}=1.09 \AA\right)$ which decreases grain boundaries and number of grains. Larger the grains which causes less number of insulating grain boundaries that helps to decrease resistivity [20]. The maximum conductivity of doped sample is also due to availability of extra charge carriers than undoped sample. With increasing concentration of samarium some of $\mathrm{Sm}^{3+}$ ions occupying octahedral B site, decreases the number of $\mathrm{Fe}^{3+}$ ions on B site means decrease in charges. So the maximum number of $\mathrm{Fe}^{2+}$ and $\mathrm{Fe}^{3+}$ ions and enhanced rate of electron exchange between them gives the maximum value of a.c conductivity, same behavior was observed by MohdHashim et. al for Ni-Cu-Zn ferrite [19].

\section{Acknowledgement:-}

One of the author A. B. Mugutkar is thankful to UGC New Delhi for financial assistance under Minor Research Project.

\section{Conclusion:-}

The samarium doped cobalt zinc ferrite was successfully synthesized by sol-gel method. The dielectric constant, dielectric loss and dielectric loss tangent were decreased with the increase of $\mathrm{Sm}^{3+}$ concentration. The dielectric dispersion with frequency was observed and explained on the basis of hopping mechanism of electron. The low dielectric constant is essential for high frequency application. 


\section{References:-}

1. G. B. Alcantara, L. G. Paterno, F. J. Fonseca, M. A. Pereira-da-Silva, P. C. Morais, M. A. Soler. Phys. Chem. Chem. Phys. 2013, 15(45), 19853-61.

2. F. E. Kruisa, H. Fissana, A. Peleda. J. Aerosol Sci. 1998, 29, 511-535.

3. W. Wang, S. P. Gumfekar, Q. Jiao, B. Zhao. J. Mater. Chem. C. 2013, 1, 2851-2859.

4. V. V. Jadhav, M. K. Zate, S. Liu, M. Naushad, R. S. Mane, K. N. Hui, S. H. Han. Appl. Nanosci. 2016, 6, 511519.

5. S. D. Waghmare, V. V. Jadhav, S. K. Gore, S. J. Yoon, S. B. Ambade, B. J. Lokhande, R. S. Mane, S. H. Han. Mater. Res. Bul. 2012, 47, 4169-4174.

6. S. K. Gore, U. B. Tumberphale, S. S. Jadhav, R. S. Kawale, M. Naushad, R. S. Mane. Phys. B Phys. Cond. Mat. 2018, 530, 177-182.

7. S. K. Gore, S. S. Jadhav, U. B. Tumberphale, S. M. Shaikh, M. Naushad, R. S. Mane. Solid State Sci. 2017, 74, 88-94.

8. R. S. Devan, Y. D. Kolekar, B. K. Chougule. J. Phys.: Condens, Matter 2006, 18, 9809.

9. K. Verma, A. Kumar, D. Varshney. J. Alloy. Comp. 2012, 526, 91-97.

10. C. Murugesan, G. Chandrasekaran. Rsc. Adv. 2015, 5, 73714-73725.

11. P. P. Hankare, K. R. Sanadi, K. M. Garadkar, D. R. Patil, I. S. Mulla. J. Alloy. Comp. 2013, 553, $383-388$.

12. K. Iwauchi, Jap. J. Appl. Phys. 1971, 10, 11.

13. S. S. Jadhav, S. E. Shirsath, B. G. Toksha, S. J. Shukla, K. M. Jadhav. Chin. J. Chem. Phys. $2008,21,381$.

14. M. K. Zate, V. V. Jadhav, S. K. Gore, J. H. Shandkar, S. U. Ekar, A. Alosta, M. Naushad, R. S. Mane. J. Anal. Appl. Pryo. 2016, 122, 224-229.

15. S. K. Gore, R. S. Mane, M. Naushad, S. S. Jadhav, M. K. Zate, Z. A. Alothman, K. N. Hui. Dalton Trans. 2015, 44, 6384.

16. J.C.Maxwell Oxford university press, London, 1873, 328 .

17. K.W. Wanger. Ann. Phys. 1913, 40, 817.

18. M. A. Iqbal, M. ul-Islamn, I. Ali, H. M. Khan, G. Mustafa, I. Ali. Ceram. Int. 2013, 39, 1539-1545.

19. M. Hashim, Alimuddin, S. E. Shirsath, S. Kumar, R. Kumar, A. S. Roy, J. Shah, R.K. Kotnala. J. Alloy. Comp. 2013, 549, 348-357.

20. R. Nongjai, S. Khan, K. Asokan, H. Ahmed, I. Khan. J. Appl. Phys. 2012, 112, 084321. 